\title{
Association between the MTHFR C677T polymorphism and gastric cancer susceptibility: A meta-analysis of 5,757 cases and 8,501 controls
}

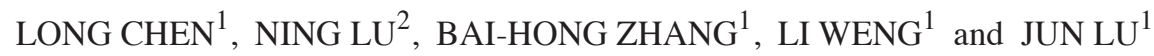 \\ ${ }^{1}$ Department of Oncology, Lanzhou Military Command General Hospital of the People's Liberation Army, Lanzhou, \\ Gansu 730050; ${ }^{2}$ Department of Oncology, Urumqi Military Command General Hospital of the People's Liberation Army, \\ Urumqi, Xinjiang 830000, P.R. China
}

Received May 25, 2014; Accepted March 26, 2015

DOI: $10.3892 / 01.2015 .3356$

\begin{abstract}
Current data regarding the association between the methylenetetrahydrofolate reductase (MTHFR) C677T polymorphism and the risk of developing gastric cancer are insufficient to draw definite conclusions. Therefore, the present meta-analysis was conducted to achieve a more precise estimation of the association. MEDLINE, EMBASE and Wanfang database searches resulted in the identification of 28 eligible studies describing 5,757 cases and 8,501 controls. The strength of the association between the MTHFR C677T polymorphism and gastric cancer risk were evaluated using crude odds ratios (ORs), with 95\% confidence intervals (CIs). The pooled ORs were determined using homozygous (TT vs. CC), heterozygous (CT vs. CC), dominant (TT+CT vs. CC) and recessive (TT vs. $\mathrm{CC}+\mathrm{CT}$ ) models. When all studies were pooled into the meta-analysis, significant associations were identified between the MTHFR C677T polymorphism and the risk of gastric cancer (homozygous model: OR, 1.39; 95\% CI, 1.20-1.62; heterozygous model: OR, 1.18; 95\% CI, 1.05-1.32; dominant model: OR, 1.23; 95\% CI, 1.10-1.38; recessive model: OR, 1.26; 95\% CI, 1.12-1.42). Stratification of the data by ethnicity identified a statistically significantly elevated risk of gastric cancer in Asian MTHFR C677T polymorphism populations (homozygous model: OR, 1.64; 95\% CI, 1.43-1.90; heterozygous model: OR, 1.30; 95\% CI, 1.16-1.45; dominant model: OR, 1.39; 95\% CI, 1.25-1.54; recessive model: OR, 1.41; 95\% CI, 1.25-1.51), but not in Caucasian populations (homozygous model: OR, 1.15; 95\% CI, 0.89-1.48;
\end{abstract}

Correspondence to: Dr Ning Lu, Department of Oncology, Urumqi Military Command General Hospital of the People's Liberation Army, 359 Youhao North Road, Urumqi, Xinjiang 830000, P.R. China

E-mail: ninglu72@126.com

Key words: gastric cancer, case-control, meta-analysis, methylenetetrahydrofolate reductase, polymorphism heterozygous model: OR, 1.03; 95\% CI, 0.84-1.25; dominant model: OR, 1.05; 95\% CI, 0.86-1.28; recessive model: OR, 1.09; 95\% CI, 0.91-1.31). Following adjustment for heterogeneity, the current meta-analysis demonstrated that the MTHFR C677T polymorphism was not associated with the risk of gastric cancer in Caucasian individuals. Furthermore, no evidence of publication bias was observed. Thus, the current meta-analysis indicates that the MTHFR C677T allele may be a low-penetrant risk factor for the development of gastric cancer in Asian populations.

\section{Introduction}

Gastric cancer is the second most common cause of cancer-associated mortality in the world. In particular, it is one of the predominant cancer types in Korean and East Asian populations (1-4). Gastric cancer is a multifactorial malignant disorder caused by a wide range of risk factors, including genetic predisposition, the environment and Helicobacter pylori infection (1). Persistent $H$. pylori infection in the human stomach elicits a chronic inflammatory response, the extent of which may vary between individuals depending on the genetic makeup of the host. This phenomenon may aid in explaining the diverse range of outcomes observed in individuals infected with $H$. pylori. Therefore, polymorphisms in genes that are important in the host inflammatory response to this infection may alter an individual's susceptibility to gastric cancer (2). Notably, associations have been identified between gastric cancer and the expression of various genes involved in folate metabolism, such as methionine synthase (MTR), methylenetetrahydrofolate reductase (MTHFR) and MTR reductase (MTRR) (3).

MTHFR is an essential component of folate metabolism that has been indicated to be involved in DNA methylation and synthesis (4). The common MTHFR C677T polymorphism results in the substitution of alanine by valine, producing of a thermolabile variant that retains only $\sim 30 \%$ of the activity of the wild-type MTHFR enzyme (5). The association between this gene polymorphism and the risk of gastric cancer has drawn increasing attention in the scientific community and has been investigated extensively, with 27 original studies $(3,6-32)$ examining the role of the 
MTHFR C667T polymorphism in the development of gastric cancer. However, these studies have yielded conflicting results, partially due to the small effect of the gene polymorphism on the risk of gastric cancer and the relatively small sample sizes used. Therefore, the aim of the current meta-analysis was to determine a more precise estimation of the association between the MTHFR C677T polymorphism and gastric cancer risk.

\section{Materials and methods}

Identification and eligibility of relevant studies. The current meta-analysis was performed according to the guidelines for systematic reviews of genetic association studies (33). Two investigators independently searched the MEDLINE, EMBASE and Wanfang electronic databases for studies published from inception to May 2013. Combining text words and Medical Subject Headings (MESH) terms, the following keywords were used to perform the literature search: 'MTHFR' or 'methylenetetrahydrofolate reductase' to search for MTHFR; 'gastric cancer' or 'stomach cancer' to search for gastric cancer; and 'gene', or 'polymorphism' or 'genetic variation' to search for genetic variations. The aforementioned search terms were used in conjunction with the 'explode' feature where applicable. Full studies published in the English and Chinese languages were considered for inclusion in the present study. In addition, the reference lists of all primary studies and reviews were manually searched. All case-control studies that investigated the association between the MTHFR $677 \mathrm{C}>\mathrm{T}$ polymorphism and gastric cancer were included. Furthermore, when the same series was used in more than one case-control study, the study with the largest cohort was selected.

Data extraction. The following data was extracted from each of the selected studies: First author, year of publication, ethnicity of study population, and the number of cases and controls for each C677T genotype.

Statistical analysis. Crude odds ratios (ORs) with 95\% confidence intervals (CIs) were calculated to evaluate the association between the MTHFR $677 \mathrm{C}>\mathrm{T}$ polymorphism and the risk of gastric cancer. The pooled ORs were obtained for homozygous (TT vs. CC), heterozygous (CT vs. CC), dominant $(\mathrm{TT}+\mathrm{CT}$ vs. $\mathrm{CC})$ and recessive $(\mathrm{TT}$ vs. $\mathrm{CC}+\mathrm{CT})$ models. Heterogeneity assumption was examined using the $\chi^{2}$-based $\mathrm{Q}$ test (34), with $\mathrm{P} \leq 0.01$ considered to indicate heterogeneity among studies. Subsequently, the pooled OR estimate was calculated for each study using the fixed-effects model (Mantel-Haenszel method) (35). Otherwise, the random-effects model (DerSimonian and Laird method) was used (36). To evaluate the source of between-study heterogeneity, Galbraith plots was constructed to identify outliers that may be acting as major sources of between-study heterogeneity. In addition, subgroup analyses by ethnicity were performed. The potential publication bias of the present study was estimated by constructing a funnel plot in which the standard error of $\log (\mathrm{OR})$ was plotted against $\log (\mathrm{OR})$, for each study. Funnel plot asymmetry, which indicates a possible publication bias, was evaluated using Egger's linear regression test. Furthermore, the significance of the intercept was determined by performing a

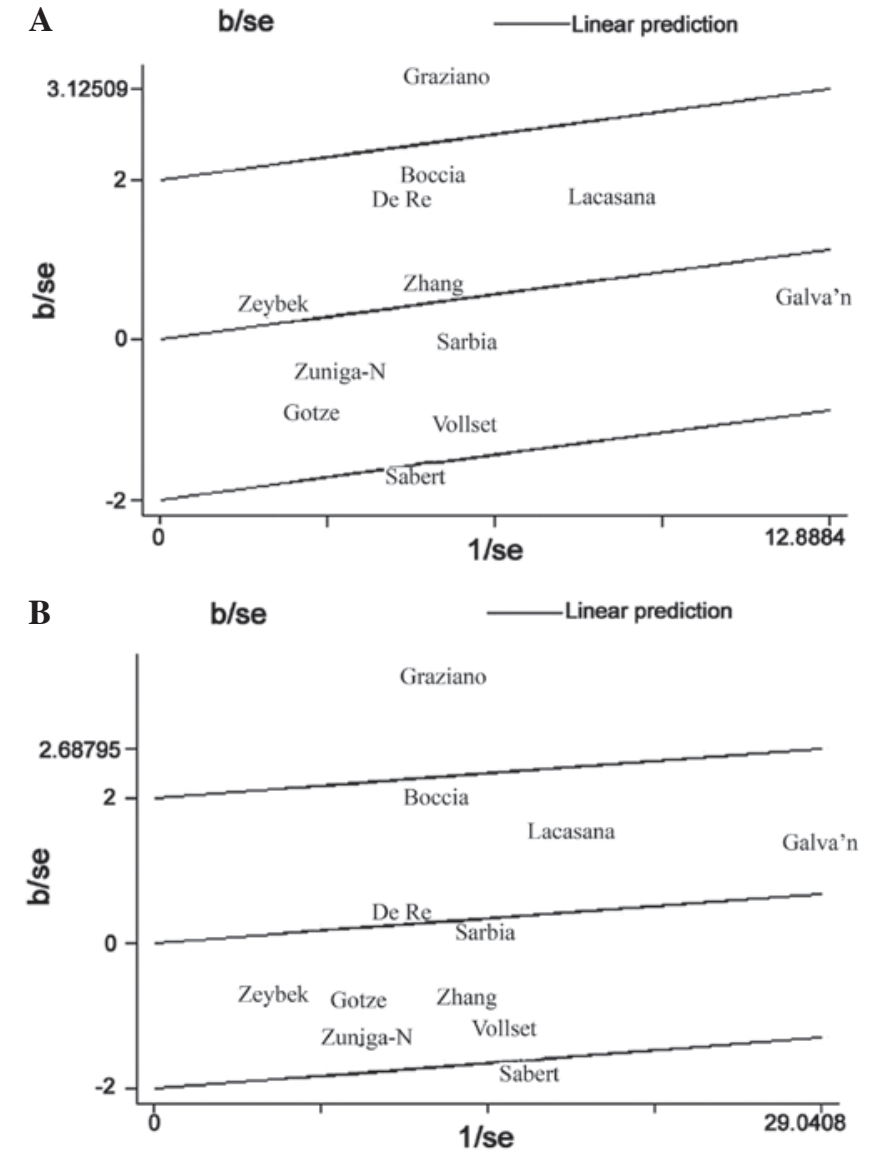

Figure 1. Galbraith plots of the association between the methylenetetrahydrofolate reductase T677C polymorphism and gastric cancer risk in Caucasian populations, using a (A) homozygous and (B) dominant model. Each author name represents a respective and separate study included in the current meta-analysis. b, bias; se, standard error.

t-test, as proposed by Egger (37). $\mathrm{P}<0.05$ was considered to indicate a statistically significant publication bias (38). All statistical analyses were performed using Stata software (version 10.0; Stata Corporation, College Station, TX, USA).

\section{Results}

Study characteristics. A total of 27 publications met the inclusion criteria of the current meta-analysis (3,6-32), thus, a total of 5,757 cases and 8,501 controls were used in the pooled analyses. Tables I and II list the included studies and their major characteristics. In the 27 studies, the sample sizes ranged between 72 and 1,230 individuals. Furthermore, the studies included 12 European and 17 Asian populations, and the majority of controls were matched for gender and age.

Meta-analysis of the MTHFR C677T polymorphism. Table III indicates the major results of the current meta-analysis. When all the studies were pooled into the meta-analysis, the MTHFR $\mathrm{T}$ allele was determined to be associated with a significantly increased risk of developing gastric cancer (homozygous model: OR, 1.39; 95\% CI, 1.20-1.62; heterozygous model: OR, 1.18; 95\% CI, 1.05-1.32; dominant model: OR, 1.23; 95\% CI, 1.10-1.38; recessive model: OR, 1.26; 95\% CI, 1.12-1.42) $(\mathrm{P}<0.001)$. In the subgroup analysis by ethnicity, no significantly 
Table I. Major characteristics of all studies included in the current meta-analysis.

\begin{tabular}{|c|c|c|c|c|c|}
\hline First author (ref.) & Year of publication & Country & Ethnicity & Cases, $\mathrm{n}$ & Controls, $\mathrm{n}$ \\
\hline Miao et al (8) & 2002 & China & Asian & 217 & 468 \\
\hline Gao et al (7) & 2002 & China & Asian & 107 & 200 \\
\hline Gao et al (32) & 2001 & China & Asian & 107 & 200 \\
\hline Stolzenberg-Solomon et al (21) & 2003 & China & Asian & 90 & 398 \\
\hline Bi et al (9) & 2005 & China & Asian & 309 & 188 \\
\hline Shen et al (10) & 2005 & China & Asian & 320 & 313 \\
\hline Sarbia et al (14) & 2005 & Germany & Caucasian & 332 & 255 \\
\hline Wang et al (20) & 2005 & China & Asian & 129 & 315 \\
\hline Si et al (18) & 2005 & China & Asian & 122 & 101 \\
\hline Kim et al (19) & 2005 & Korea & Asian & 133 & 445 \\
\hline Li et al (30) & 2006 & China & Asian & 170 & 140 \\
\hline Graziano et al (13) & 2006 & Italy & Caucasian & 162 & 164 \\
\hline Lacasaña-Navarro et al (24) & 2006 & Mexico & Caucasian & 201 & 427 \\
\hline Weng et al (17) & 2006 & China & Asian & 38 & 34 \\
\hline Zeybek et al (26) & 2007 & Turky & Caucasian & 35 & 144 \\
\hline Wang et al (16) & 2007 & China & Asian & 467 & 540 \\
\hline Götze et al (12) & 2007 & Germany & Caucasian & 103 & 106 \\
\hline Zhang et al (3) & 2007 & USA & Caucasian & 295 & 399 \\
\hline $\mathrm{Mu}$ et al (6) & 2007 & China & Asian & 194 & 391 \\
\hline Boccia et al (11) & 2007 & Italy & Caucasian & 102 & 254 \\
\hline Vollset et al (25) & 2007 & Europe & Caucasian & 295 & 399 \\
\hline Li et al (15) & 2007 & China & Asian & 170 & 140 \\
\hline Zúñiga-Noriega et al (23) & 2008 & Mexico & Caucasian & 51 & 83 \\
\hline Galván-Portillo et al (22) & 2009 & Mexico & Caucasian & 248 & 478 \\
\hline Yang et al (31) & 2010 & China & Asian & 139 & 165 \\
\hline De Re et al (27) & 2010 & Italy & Caucasian & 57 & 454 \\
\hline Saberi et al (29) & 2012 & Iran & Caucasian & 450 & 780 \\
\hline Gao et al (28) & 2013 & China & Asian & 264 & 535 \\
\hline
\end{tabular}

increased risk of gastric cancer was identified in Caucasians with the MTHFR C677T polymorphism [homozygous model: OR, 1.15; 95\% CI, 0.89-1.48 (Fig. 1A); heterozygous model: OR, 1.03; 95\% CI, 0.84-1.25; dominant model: OR, 1.05; 95\% CI, 0.86-1.28 (Fig. 1B); recessive model: OR, 1.09; 95\% CI, 0.91-1.31]; however, significantly increased risks were identified in Asian populations (homozygous model: OR, 1.64; 95\% CI, 1.43-1.90; heterozygous model: OR, 1.30; 95\% CI, 1.16-1.45; dominant model: OR, 1.39; 95\% CI, 1.25-1.54; recessive model: OR, $1.41 ; 95 \% \mathrm{CI}, 1.25-1.51)$.

Publication bias. Begg's funnel plot and Egger's test were performed to assess the publication bias of studies included in the current meta-analysis. No evidence of marked asymmetry was observed in the funnel plot (Fig. 2). Furthermore, Egger's test did not indicate any statistical evidence of asymmetry and therefore, publication bias (homozygous model, $\mathrm{P}=0.866$; heterozygous model, $\mathrm{P}=0.940$; dominant model, $\mathrm{P}=0.851$; recessive model, $\mathrm{P}=0.358$ ).

\section{Discussion}

It is well documented that individual susceptibility to the development of cancer can vary, even when exposed to the same environmental carcinogens $(2,33)$. This difference in susceptibility may be associated with genetic variations, such as polymorphisms, in genes involved in carcinogenesis. Therefore, genetic susceptibility to the development of cancer has been the focus of considerable scientific research. Recently, extensive investigation of genetic variants of the MTHFR gene has taken place to determine its role in the etiology of gastric cancer. Numerous studies have examined the role of the MTHFR C677T polymorphism in gastric cancer risk, however, the data is contradictory. Therefore, to improve understanding of the association between the MTHFR C677T polymorphism and the risk of gastric cancer, the present meta-analysis of pooled data from a large sample was conducted. To the best of our knowledge, this is the first meta-analysis regarding the association between the MTHFR C677T polymorphism and the risk of gastric cancer to be conducted. In addition, subgroup analysis and heterogeneity evaluations were performed. The results indicated that the MTHFR $677 \mathrm{~T}$ allele is associated with a significantly increased risk of developing gastric cancer. Furthermore, significant associations were identified in Asian individuals, but not in Caucasian individuals, indicating a possible role of ethnicity in the risk of gastric cancer, due to differences in genetic backgrounds, geography and environment (37). However, it is possible that the effect 
Table II. Genotypes of the methylenetetrahydrofolate reductase C677T polymorphism included in the meta-analysis.

\begin{tabular}{|c|c|c|c|c|c|c|c|}
\hline \multirow[b]{2}{*}{ First author (ref.) } & \multirow[b]{2}{*}{ Year of publication } & \multicolumn{3}{|c|}{ Cases, $\mathrm{n}$} & \multicolumn{3}{|c|}{ Controls, $\mathrm{n}$} \\
\hline & & $\mathrm{CC}$ & $\mathrm{CT}$ & $\mathrm{TT}$ & $\mathrm{CC}$ & $\mathrm{CT}$ & TT \\
\hline Gao et al (32) & 2001 & 22 & 61 & 24 & 63 & 99 & 38 \\
\hline Miao et al (8) & 2002 & 47 & 107 & 63 & 151 & 217 & 100 \\
\hline Gao et al (7) & 2002 & 22 & 61 & 24 & 63 & 99 & 38 \\
\hline Stolzenberg-Solomon et al (21) & 2003 & 17 & 36 & 37 & 65 & 209 & 124 \\
\hline Bi et al (9) & 2005 & 139 & 150 & 20 & 97 & 76 & 15 \\
\hline Shen et al (10) & 2005 & 105 & 171 & 44 & 113 & 172 & 28 \\
\hline Sarbia et al (14) & 2005 & 138 & 153 & 41 & 107 & 115 & 33 \\
\hline Wang et al (20) & 2005 & 25 & 45 & 59 & 74 & 143 & 98 \\
\hline Si et al (18) & 2005 & 58 & 48 & 16 & 49 & 43 & 9 \\
\hline Kim et al (19) & 2005 & 42 & 64 & 27 & 143 & 239 & 63 \\
\hline Li et al (30) & 2006 & 61 & 78 & 31 & 67 & 56 & 17 \\
\hline Graziano et al (13) & 2006 & 34 & 86 & 42 & 67 & 68 & 29 \\
\hline Lacasaña-Navarro et al (24) & 2006 & 56 & 85 & 60 & 144 & 179 & 104 \\
\hline Weng et al (17) & 2006 & 14 & 19 & 5 & 15 & 11 & 8 \\
\hline Zeybek et al (26) & 2007 & 18 & 12 & 5 & 64 & 65 & 15 \\
\hline Wang et al (16) & 2007 & 74 & 203 & 190 & 119 & 234 & 187 \\
\hline Götze et al (12) & 2007 & 46 & 45 & 12 & 41 & 49 & 16 \\
\hline Zhang et al (3) & 2007 & 146 & 116 & 33 & 185 & 178 & 36 \\
\hline Mu et al (6) & 2007 & 50 & 106 & 38 & 135 & 199 & 57 \\
\hline Boccia et al (11) & 2007 & 29 & 51 & 22 & 98 & 115 & 41 \\
\hline Vollset et al (25) & 2007 & 109 & 104 & 32 & 248 & 277 & 94 \\
\hline Li et al (15) & 2007 & 61 & 78 & 31 & 67 & 56 & 17 \\
\hline Zúñiga-Noriega et al (23) & 2008 & 16 & 23 & 12 & 17 & 49 & 17 \\
\hline Galván-Portillo et al (22) & 2009 & 37 & 132 & 79 & 89 & 217 & 172 \\
\hline Yang et al (31) & 2010 & 44 & 80 & 15 & 62 & 75 & 28 \\
\hline De Re et al (27) & 2010 & 18 & 25 & 14 & 152 & 238 & 64 \\
\hline Saberi et al (29) & 2012 & 422 & 308 & 50 & 198 & 172 & 35 \\
\hline Gao et al (28) & 2013 & 115 & 105 & 44 & 277 & 207 & 51 \\
\hline
\end{tabular}

of the MTHFR $677 \mathrm{C}$ allele is masked by the expression of thus far unidentified causal genes involved in the development of gastric cancer in Caucasian individuals. In addition, the ethnic differences observed in the present study may be due to chance, as studies with small sample sizes typically lack the statistical power to detect marginal effects and may generate a fluctuated risk estimate (39). Considering the limited number of studies included in the present meta-analysis and the small Caucasian populations, the current results should be interpreted with caution.

Heterogeneity is a potential problem that may affect the interpretation of the results of all meta-analyses. In the present meta-analysis, significant between-study heterogeneity for OR was identified in the overall comparisons (homozygous model, $\mathrm{P}=0.011$; heterozygous model, $\mathrm{P}=0.003$; dominant model, $\mathrm{P}=0.016$; recessive model, $\mathrm{P}=0.039)$. However, subgroup analysis by ethnicity demonstrated that heterogeneity was only evident between studies involving Caucasian populations (homozygous model, $\mathrm{P}=0.006$; recessive model, $\mathrm{P}=0.002$ ) but not for those involving Asian populations (Table III) . Heterogeneity may also occur in poorly-designed studies that do not exclude biases, as these biases may affect the estimation of the real effects and cause incorrect conclusions to be drawn $(40,41)$. Therefore, Galbraith plots were used to identify the outlier studies with poor quality designs. Following subgroup analysis of Caucasian studies, the Galbraith plot identified two studies that appeared to be major sources of heterogeneity (Fig. 1), with no between-study heterogeneity observed among the remaining 10 studies (homozygous model, $\mathrm{P}=0.345$; recessive model, $\mathrm{P}=0.190)$. As a result, the fixed-effects model was used to pool the ORs from the two outlier studies, effectively removing heterogeneity from the current meta-analysis and thus confirming that the two excluded studies contributed the heterogeneity. Following adjustment for heterogeneity, the current data demonstrated that the MTHFR MTHFR C677T polymorphism was significantly associated with an increased risk of gastric cancer in Asian individuals, but not in Caucasian individuals.

A number of limitations should be taken into consideration when interpreting the findings of the current meta-analysis. First, the controls were not uniformly defined. Although the majority of the control subjects were recruited from healthy populations, certain individuals exhibited benign medical disorders. As a number of studies in the present meta-analysis included control groups that may have different risks of developing gastric cancer, 
Table III. Pooled OR data obtained in the current meta-analysis.

\begin{tabular}{|c|c|c|c|c|c|c|}
\hline Contrast model & Studies, $\mathrm{n}$ & OR $(95 \% \mathrm{CI})$ & P-value & Model & $\mathrm{I}^{2}, \%$ & P-value \\
\hline \multicolumn{7}{|l|}{ Total studies } \\
\hline Homozygous & 27 & $1.39(1.20-1.62)$ & $<0.001$ & Random & 41.5 & 0.011 \\
\hline Heterozygous & 27 & $1.18(1.05-1.32)$ & 0.006 & Random & 47.3 & 0.003 \\
\hline Recessive & 27 & $1.26(1.12-1.42)$ & $<0.001$ & Random & 34.1 & 0.039 \\
\hline Dominant & 27 & $1.23(1.10-1.38)$ & $<0.001$ & Random & 52.8 & 0.016 \\
\hline \multicolumn{7}{|l|}{ Caucasian } \\
\hline Homozygous & 12 & $1.15(0.89-1.48)$ & 0.791 & Random & 58.2 & 0.006 \\
\hline $\begin{array}{l}\text { Homozygous (adjusted for } \\
\text { heterogeneity) }\end{array}$ & 10 & $1.13(0.93-1.36)$ & 0.215 & Fixed & 10.6 & 0.345 \\
\hline Heterozygous & 12 & $1.03(0.84-1.25)$ & $<0.001$ & Fixed & 0.0 & 0.674 \\
\hline Recessive & 12 & $1.09(0.91-1.31)$ & 0.367 & Fixed & 32.1 & 0.134 \\
\hline Dominant & 12 & $1.05(0.86-1.28)$ & 0.609 & Random & 63.3 & 0.002 \\
\hline $\begin{array}{l}\text { Dominant (adjusted for } \\
\text { heterogeneity) }\end{array}$ & 10 & $1.00(0.88-1.14)$ & 0.968 & Fixed & 27.6 & 0.19 \\
\hline \multicolumn{7}{|l|}{ Asian } \\
\hline Homozygous & 17 & $1.64(1.43-1.90)$ & $<0.001$ & Fixed & 0.0 & 0.674 \\
\hline Heterozygous & 17 & $1.30(1.16-1.45)$ & $<0.001$ & Fixed & 2.6 & 0.423 \\
\hline Recessive & 17 & $1.41(1.25-1.61)$ & $<0.001$ & Fixed & 8.1 & 0.361 \\
\hline Dominant & 17 & $1.39(1.25-1.54)$ & $<0.001$ & Fixed & 0.0 & 0.729 \\
\hline
\end{tabular}

OR, odds ratio; CI, confidence interval; $\mathrm{I}^{2}$, index of heterogeneity.

A

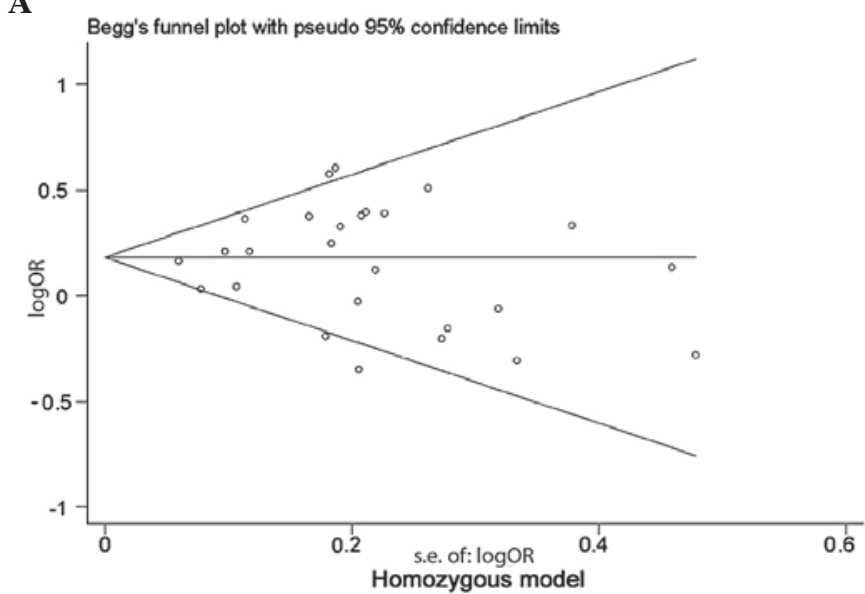

C

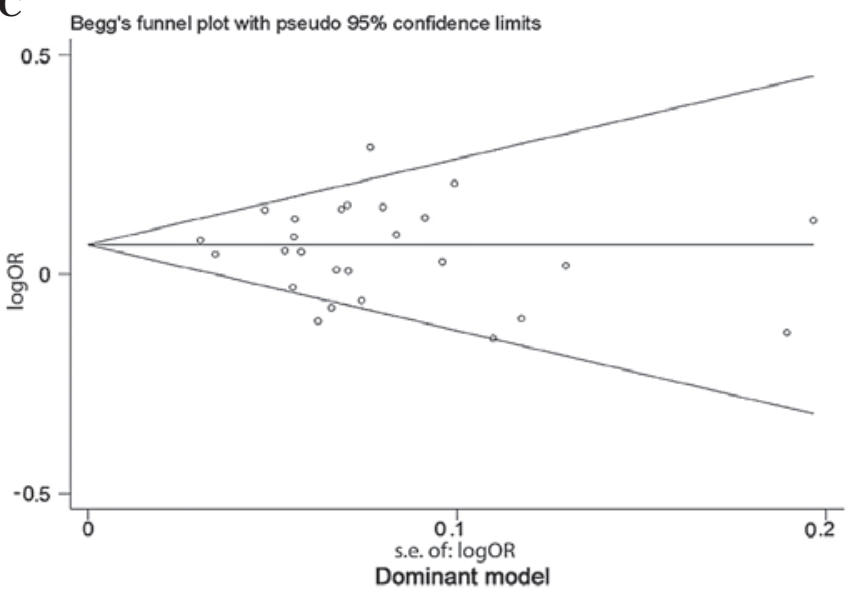

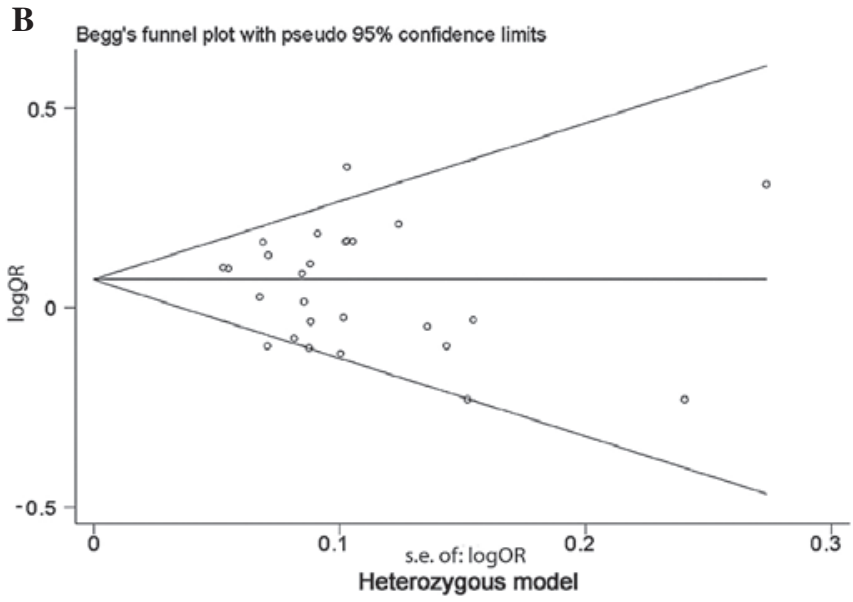

D Begg's funnel plot with pseudo $95 \%$ confidence limits

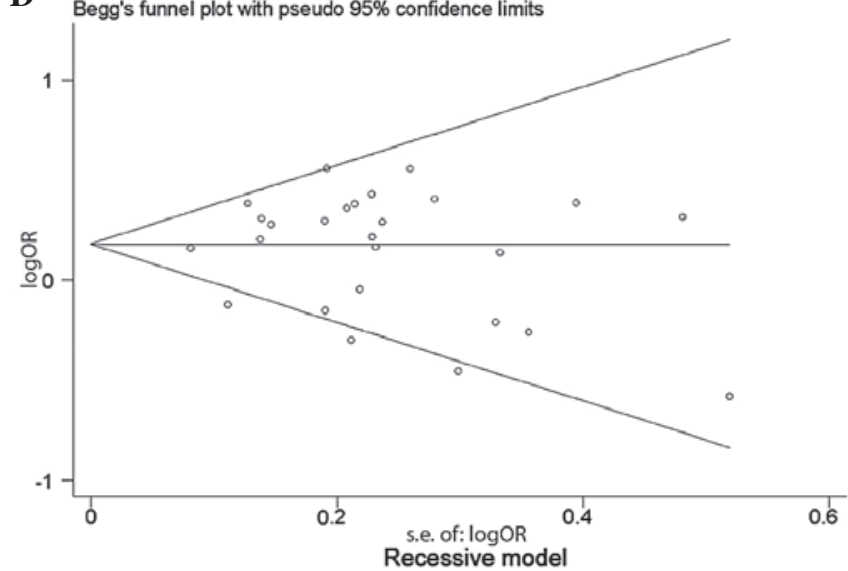

Figure 2. Begg's funnel plots for assessing the publication bias risk, using (A) homozygous $(\mathrm{P}=0.866)$, (B) heterozygous $(\mathrm{P}=0.940)(\mathrm{C})$ dominant $(\mathrm{P}=0.851)$ and (D) recessive $(\mathrm{P}=0.358)$ models. s.e., standard error; $\mathrm{OR}$, odds ratio. 
non-differential misclassification bias may have occurred. Second, the current results were based on unadjusted estimates. If individual data is made available, future studies should consider using it to perform more precise analyses, as individual data would allow for the adjustment for additional co-variates, such as age, smoking status, environmental factors and lifestyle. Despite the aforementioned limitations, the current meta-analysis exhibited high statistical power, as a large number of cases and controls were pooled from different studies. In addition, no publication bias was detected, indicating that the overall pooled effects were unbiased.

In conclusion, the current meta-analysis indicated that the MTHFR T allele is a low-penetrant genetic risk factor for the development of gastric cancer. However, well-matched case-control studies with homogeneous cancer patients of multi-ethnic groups using standardized unbiased genotyping methods are warranted in the future. Furthermore, it is recommended that investigations should be conducted into the effects of gene-gene and gene-environment interactions on the development of gastric cancer.

\section{References}

1. Ahn DH, Rah H, Choi YK, et al: Association of the miR-146aC>G, miR-149T $>C$, miR-196a2T $>C$, and miR-499A $>$ G polymorphisms with gastric cancer risk and survival in the Korean population. Mol Carcinog (Suppl 1) 52: E39-E51, 2013.

2. Persson C, Canedo P, Machado JC, El-Omar EM and Forman D: Polymorphisms in inflammatory response genes and their association with gastric cancer: A HuGE systematic review and meta-analyses. Am J Epidemiol 173: 259-270, 2011.

3. Zhang FF, Terry MB, Hou L, et al: Genetic polymorphisms in folate metabolism and the risk of stomach cancer. Cancer Epidemiol Biomarkers Prev 16: 115-121, 2007.

4. Warshauer ME, Silverman DT, Schottenfeld D and Pollack ES: Stomach and colorectal cancers in Puerto Rican-born residents of New York City. J Natl Cancer Inst 76: 591-595, 1986.

5. Jacques PF, Bostom AG, Williams RR, et al: Relation between folate status, a common mutation in methylenetetrahydrofolate reductase, and plasma homocysteine concentrations. Circulation 93: 7-9, 1996.

6. Mu LN, Cao W, Zhang ZF, et al: Polymorphisms of 5, 10-methylenetetralydrofolate reductase (MTHFR), fruit and vegetable intake, and the risk of stomach cancer. Biomarkers 12: 61-75, 2007.

7. Gao C, Wu J, Ding J, et al: Polymorphisms of methylenetetrahydrofolate reductase $\mathrm{C} 677 \mathrm{~T}$ and the risk of stomach cancer. Zhonghua Liu Xing Bing Xue Za Zhi 23: 289-292, 2002 (In Chinese)

8. Miao X, Xing D, Tan W, Qi J, Lu W and Lin D: Susceptibility to gastric cardia adenocarcinoma and genetic polymorphisms in methylenetetrahydrofolate reductase in an at-risk Chinese population. Cancer Epidemiol Biomarkers Prev 11: 1454-1458, 2002.

9. Bi J, Cai L and Zheng Z: Study on C667T gene polymorphism and susceptibility to gastric cancer. Chin J Public 21: 661, 2005.

10. Shen H, Newmann AS, Hu Z, et al: Methylenetetrahydrofolate reductase polymorphisms/haplotypes and risk of gastric cancer: A case-control analysis in China. Oncol Rep 13: 355-360, 2005.

11. BocciaS,GianfagnaF,PersianiR,etal:Methylenetetrahydrofolate reductase C677T and A1298C polymorphisms and susceptibility to gastric adenocarcinoma in an Italian population. Biomarkers 12: 635-644, 2007.

12. Götze T, Röcken C, Röhl FW, et al: Gene polymorphisms of folate metabolizing enzymes and the risk of gastric cancer. Cancer Lett 251: 228-236, 2007.

13. Graziano F, Kawakami K, Ruzzo A, et al: Methylenetetrahydrofolate reductase $677 \mathrm{C} / \mathrm{T}$ gene polymorphism, gastric cancer susceptibility and genomic DNA hypomethylation in an at-risk Italian population. Int J Cancer 118: 628-632, 2006.

14. Sarbia M, Geddert H, Kiel S, et al: Methylenetetrahydrofolate reductase C677T polymorphism and risk of adenocarcinoma of the upper gastrointestinal tract. Scand J Gastroenterol 40: 109-111, 2005.
15. Li S, Ji M, He N and Lu Z: Application of microarray-based method for methylenetetrahydrofolate reductase (MTHFR) polymorphisms in the risk of gastric carcinoma in east China population. J Nanosci Nanotechnol 7: 3245-3249, 2007.

16. Wang Y, Guo W, He Y, et al: Association of MTHFR C677T and SHMT1 C1420T with susceptibility to ESCC and GCA in a high incident region of Northern China. Cancer Causes Control 18: 143-152, 2007.

17. Weng YR, Sun DF, Fang JY, Gu WQ and Zhu HY: Folate levels in mucosal tissue but not methylenetetrahydrofolate reductase polymorphisms are associated with gastric carcinogenesis. World J Gastroenterol 12: 7591-7597, 2006.

18. Si PR, Fang DC, Zhang H, Yang LQ, Luo YH and Liao HY: The relationship between methylenetetrahydrofolate reductase gene polymorphism and microsatellite instability in gastric cancer. Zhonghua Liu Xing Bing Xue Za Zhi 26: 794-799, 2005 (In Chinese).

19. Kim JK, Kim S, Han JH, et al: Polymorphisms of 5,10-methylenetetrahydrofolate reductase and risk of stomach cancer in a Korean population. Anticancer Res 25: 2249-2252, 2005.

20. Wang LD, Guo RF, Fan ZM, et al: Association of methylenetetrahydrofolate reductase and thymidylate synthase promoter polymorphisms with genetic susceptibility to esophageal and cardia cancer in a Chinese high-risk population. Dis Esophagus 18: 177-184, 2005.

21. Stolzenberg-Solomon RZ, Qiao YL, Abnet CC, et al: Esophageal and gastric cardia cancer risk and folate- and vitamin $\mathrm{B}(12)$-related polymorphisms in Linxian, China. Cancer Epidemiol Biomarkers Prev 12: 1222-1226, 2003

22. Galván-Portillo MV, Cantoral A, Oñate-Ocaña LF, et al: Gastric cancer in relation to the intake of nutrients involved in one-carbon metabolism among MTHFR 677 TT carriers. Eur J Nutr 48: 269-276, 2009.

23. Zúñiga-Noriega JR, Velazco-Campos Mdel R, Aguirre-Rodríguez A, et al: C677T polymorphism of the MTHFR gene and the risk of developing distal gastric cancer in a Mexican population. Rev Gastroenterol Mex 72: 355-358, 2007 (In Spanish).

24. Lacasaña-NavarroM,Galván-PortilloM,ChenJ,López-CervantesM and López-Carrillo L: Methylenetetrahydrofolate reductase $677 \mathrm{C}>\mathrm{T}$ polymorphism and gastric cancer susceptibility in Mexico. Eur J Cancer 42: 528-533, 2006

25. Vollset SE, Igland J, Jenab M, et al: The association of gastric cancer risk with plasma folate, cobalamin, and methylenetetrahydrofolate reductase polymorphisms in the European Prospective Investigation into Cancer and Nutrition. Cancer Epidemiol Biomarkers Prev 16: 2416-2424, 2007.

26. Zeybek U, Yaylim I, Yilmaz H, et al: Methylenetetrahydrofolate reductase C677T polymorphism in patients with gastric and colorectal cancer. Cell Biochem Funct 25: 419-422, 2007.

27. De Re V, Cannizzaro R, Canzonieri V, et al: MTHFR polymorphisms in gastric cancer and in first-degree relatives of patients with gastric cancer. Tumour Biol 31: 23-32, 2010.

28. Gao S, Ding LH, Wang JW, Li CB and Wang ZY: Diet folate, DNA methylation and polymorphisms in methylenetetrahydrofolate reductase in association with the susceptibility to gastric cancer. Asian Pac J Cancer Prev 14: 299-302, 2013.

29. Saberi S, Zendehdel K, Jahangiri S, et al: Impact of methylenetetrahydrofolate reductase $\mathrm{C} 677 \mathrm{~T}$ polymorphism on the risk of gastric cancer and its interaction with Helicobacter pylori infection. Iran Biomed J 16: 179-184, 2012.

30. Li S, Cai MJ, Hou P and He NY: Single nucleotide polymorphisms(C677T and A1298C) in methylenetetrahy-drofolate reductase gene and susceptibility to gastric carcinoma. J Southeast Univ 25: 321-324, 2006.

31. Yang XX, Li FX, Yi JP, Li X, Sun JZ and Hu NY: Impact of methylenetetrahydrofolate reductase $\mathrm{C} 677 \mathrm{~T}$ polymorphism on the risk of gastric cancer, colorectal cancer and lung cancer. Guangdong Med J 31: 2375-2378, 2010.

32. Gao CM, Wu JZ, Ding JH, et al: MTHFR C677T genotypes, lifestyle and the risk of stomach cancer. China J Cancer Prev Treat 8: 187-190,2001.

33. Sagoo GS, Little J and Higgins JP; Human Genome Epidemiology Network: Systematic reviews of genetic association studies. PLoS Med 6: e28, 2009.

34. Cochran WG: The combination of estimates from different experiments. Biometrics 10: 101-129, 1954.

35. Mantel $\mathrm{N}$ and Haenszel W: Statistical aspects of the analysis of data from retrospective studies of disease. J Natl Cancer Inst 22: 719-748, 1959.

36. DerSimonian R and Laird N: Meta-analysis in clinical trials. Control Clin Trials 7: 177-188, 1986. 
37. Egger M, Davey Smith G, Schneider M and Minder C: Bias in meta-analysis detected by a simple, graphical test. BMJ 315 : 629-634, 1997.

38. Galbraith RF: A note on graphical presentation of estimated odds ratios from several clinical trials. Stat Med 7: 889-894, 1988.

39. Hirschhorn JN, Lohmueller K, Byrne E and Hirschhorn K: A comprehensive review of genetic association studies. Genet Med 4: 45-61, 2002.
40. Wacholder S, Chanock S, Garcia-Closas M, El Ghormli L and Rothman N: Assessing the probability that a positive report is false: An approach for molecular epidemiology studies. J Natl Cancer Inst 96: 434-442, 2004.

41. Thorlund K, Imberger G, Johnston BC, et al: Evolution of heterogeneity $\left(\mathrm{I}^{2}\right)$ estimates and their $95 \%$ confidence intervals in large meta-analyses. PLoS One 7: e39471, 2012. 